\title{
Research on the Structure of Public Fiscal Expenditure Based on the Cluster Analysis Methods
}

\author{
Qingjie Liu, Dexiao Ren \\ School of Government, Beijing Normal University, Beijing, China \\ Email: liuren8788@163.com, $\underline{\mathrm{dx0703@163.com}}$
}

Received 18 May 2015; accepted 13 June 2015; published 16 June 2015

Copyright $@ 2015$ by authors and Scientific Research Publifshing Inc.

This work is licensed under the Creative Commons Attribution International License (CC BY). http://creativecommons.org/licenses/by/4.0/

c) (i) Open Access

\begin{abstract}
The paper extracts the principal component of China's expenditure per capita of local government based on the factor and cluster analysis method, to determine the structure of fiscal expenditure by category of basic services, senior services, economics, resource protection factor, etc. Then the paper analyzes the regional differences in the distribution of fiscal expenditure structure based on the systematic cluster analysis method. The conclusion is that Beijing, Tianjin and Shanghai are the advanced service category of expenditure growth pole, which drives around cities' technology as well as education spending, and promotes regional economic growth.
\end{abstract}

\section{Keywords}

Structure of Public Fiscal Expenditure, Factor Analysis, Cluster Analysis

\section{Introduction}

There exists a long-standing dispute between economic liberalism and government interventionism on whether government spending can promote economic growth or not. With the rise and integration of neo-liberalism and neo-Keynesian, the role of government expenditure on stimulating economic growth begins to be recognized, and it is considered that different fiscal expenditure structures produce different economic growth effects, so searching for the best financial expenditure structure to maximize stimulate economic growth is becoming the focus of academic research, as well as the main content of this paper attempting to explore.

\section{Literature Review}

Research on the relationship between the structure of fiscal expenditure and economic growth began in the 20th

How to cite this paper: Liu, Q.J. and Ren, D.X. (2015) Research on the Structure of Public Fiscal Expenditure Based on the Cluster Analysis Methods. Modern Economy, 6, 700-706. http://dx.doi.org/10.4236/me.2015.66066 
century, to Solow [1] of the Solow model and the Swan [2] of the new growth model as a starting point, that education on economic growth and technological innovation has a significant impact. To the 1990s, Barro [3] and Lucas [4] use of endogenous growth model, the structure of government revenue and expenditure growth model introduced around the productive expenditure and non-productive expenditure on economic growth. The stimulatory effect was studied. Grier et al. [5], Aschauer [6], Easterly et al. [7] and other scholars in the United States developing empirical research for the study that is conducive to productive expenditure economic growth, while non-productive expenditure is a negative effect on economic growth. Research will finance the expenditure structure of productive expenditure and non-productive expenditure in recent years, more segments, Afonso et al. [8] mainly for OECD and EU countries to conduct studies on the size, structure and instability of the government on economic growth that social spending, government purchases, subsidies, government investment, the economy has a negative the growth effect.

Gong L.T., et al. (2001) [9], Gupta et al. [10], Guo Q.W., et al. [11] and other scholars believe that the role of productive expenditure growth is not obvious to the stimulation or negative, non-productive expenditure for economic growth has a positive impact. In recent years, academic research continues to focus on the structure of fiscal expenditure impact on economic growth. Ramey et al. [12] through the expenditure of US research analyze the role of government purchases to stimulate the economy, and government purchases due to temporary deficit may cause impact. Colombier [13] study the structural and economic growth in expenditure in Switzerland that in public expenditure, expenditure transportation infrastructure, education and administrative expenses to promote economic growth.

In addition to the research literature from the national level, domestic scholars in the local government and other regional areas, the structure of expenditure growth and economic relations have studied representative is Zhang Gang [14] with a regional perspective will be China's local government is divided into eastern, central and western regions, the structure of financial expenditure into capital expenditures, administrative expenses, education, science and health expenditures, expenditures and other agriculture production, the use of panel data and empirical economic growth the study.

Throughout the related fields of study abroad, mostly to the fiscal expenditure structure is divided into productive and non-productive expenditure, or further subdivided into constructive spending, consumer spending, as well as science, education spending, agriculture production and spending. Expenditure structure of financial impact of economic growth, the division is essential expenditure structure, and the current study for the division of fiscal expenditure structure often artificial division based on empirical judgment, lack of rigor, factor analysis can solve this problem. This paper attempts to use is the main factor analysis of fiscal expenditure structure is divided. In addition, studies of local government during regional analysis, only will be divided into eastern, central and west, there is no difference in the classification based on the specific expenditure structure of local government finances, the paper cluster analysis on the basis of principal component analysis as a basis for the structure of local government fiscal expenditure divided into five categories, to facilitate targeted policy recommendations.

\section{Fiscal Expenditure Structure}

First need to determine the structure of fiscal expenditure study important, factor analysis of 2012 local government expenditure projects to extract principal components to divide China financial expenditure structure of local government, to ensure that the structure of fiscal expenditure divided reality and rigor for the subsequent regression analysis foundation.

\subsection{Data}

This article uses the country's 31 provincial units as a sample to study the data source in 2013, "China Statistical Yearbook" per capita expenditure data form. Financial expenses include general public services, defense, public safety, education, science and technology, culture, sports and media, social security and employment, health care, environmental protection, urban and rural community affairs, agriculture, forestry and water affairs, transportation, exploration and the power of information and other matters, business services and other matters, financial regulatory affairs expenses, land resources and meteorological services, housing security spending, grain stockpiles affairs, debt servicing expenses, other expenses and 20. As the "other expenses" include items more vague, difficult to classify in the latter part of the analysis, the proportion of total fiscal revenue and expenditure 
of only $2.77 \%$, in the analysis of each item of expenditure of the project will be removed, the choice of expenditure for 19 .

\subsection{Factor Analysis}

Factor analysis of the complex relationship between factors combined have a few representative factors, while the internal 19 items of government spending a certain degree of relevance, in order to follow-up study by factor analysis to extract the main components, namely factor dimensionality reduction.

Former factor analysis should first degree of correlation between the 19 expenditure items were KMO and Bartlett test of sphericity test, only KMO test coefficient greater than 0.5, Bartley sphericity approximate chisquare test statistic significance probability is less than 0.05 to be able to factor analysis. The result can be seen in Table 1.

As can be seen from Table 1, the coefficient of KMO is 0.797 , greater than 0.5 , a significant probability Bartley sphericity test was 0.000 , less than 0.05 , reject independence between the variables with the original hypothesis that this study 19 Financial expenditure variables suitable for factor analysis. Principal component analysis was used to extract principal components factor to obtain the main factor in the orthogonal rotation method. Table 2 illustrates the situation for each component of the initial eigenvalues.

As can be seen the first three components of the cumulative variance contribution of up to $87.262 \%$, characteristic values were $10.428,2.793,2.252,1.108$, greater than 1 , the variance contribution rate was $54.882 \%, 14.699 \%$, $11.853 \%$, $5.829 \%$, totaled $87.262 \%$, the four principal components extracted can represent the state of local government expenditure.

\subsection{The Main Component Extraction}

Judging from the results of the factor analysis, 19 major financial expenditure information can be used on behalf of the four main ingredients, so get a load factor of each factor expenditure items by rotating the component matrix, factor rotation method is the maximum variance orthogonal rotation, results are as shown in Table 3.

Table 3 for each expenditure item factor analysis resulting in a load factor of four main components in the highest coefficient, the main ingredient in each factor loading highest expenditures are combined to obtain the financial expenditure structure consists of four main factors.

\subsection{The Structure of Fiscal Expenditure Divided}

Derived by factor analysis as shown in Table 3, the rotation matrix composition, and the results be sorted to obtain the structure of fiscal expenditure in Table 4.

Table 4 general public services, defense, public safety, education and the media, health care, environmental protection, agriculture, forestry and water affairs, transportation, resource exploration projects such as the power of information and other matters are spending most basic services and the like, and therefore classified as basic

Table 1. KMO and Bartlett test of sphericity.

\begin{tabular}{|c|c|c|}
\hline \multicolumn{2}{|c|}{ Sampling sufficient degree of Kaiser-Meyer-Olkin measure } & 0.797 \\
\hline \multirow{3}{*}{ Bartlett's test of sphericity } & The chi-square approximation & 814.948 \\
\hline & df & 171.000 \\
\hline & Sig. & 0.000 \\
\hline
\end{tabular}

Table 2. The initial eigenvalues.

\begin{tabular}{|c|c|c|c|c|c|c|}
\hline & 1 & 2 & 3 & 4 & 5 & 6 \\
\hline Total & 10.428 & 2.793 & 2.252 & 1.108 & 0.679 & 0.505 \\
\hline \% Variance & 54.882 & 14.699 & 11.853 & 5.829 & 3.572 & 2.66 \\
\hline Cumulative\% & 54.882 & 69.581 & 81.433 & 87.262 & 90.834 & 93.494 \\
\hline
\end{tabular}


Table 3. Rotation matrix components.

\begin{tabular}{|c|c|c|c|c|}
\hline \multirow{2}{*}{ Public expenditure items } & \multicolumn{4}{|c|}{ Principal component } \\
\hline & F1 & F2 & F3 & $\mathrm{F} 4$ \\
\hline General public services & 0.979 & & & \\
\hline Country anti & 0.944 & & & \\
\hline Public safety & 0.874 & & & \\
\hline Teach educate & & 0.691 & & \\
\hline Science and technology & & 0.932 & & \\
\hline Culture, sport and media & 0.811 & & & \\
\hline Social security and employment & & & 0.497 & \\
\hline Health & 0.687 & & & \\
\hline Energy saving & 0.645 & & & \\
\hline Urban and rural community affairs & & 0.895 & & \\
\hline Agriculture, forestry and water affairs & 0.901 & & & \\
\hline Transportation & 0.831 & & & \\
\hline Resource exploration power information and other matters & 0.760 & & & \\
\hline Business services and other matters & & 0.721 & & \\
\hline Financial regulatory affairs expenses & & & 0.878 & \\
\hline Weather and other matters of land and resources & & & & 0.661 \\
\hline Housing security spending & & & 0.638 & \\
\hline Grain and oil stockpiles affairs & & & & 0.880 \\
\hline Debt servicing expenses & & & 0.934 & \\
\hline
\end{tabular}

Note: the extraction method for principal component method; Kaiser rotation method has standardized orthogonal rotation method; rotation after six iterations to converge.

Table 4. Fiscal expenditure structure.

\begin{tabular}{|c|c|c|c|}
\hline $\begin{array}{c}\text { F1 } \\
\text { (Basic service category) }\end{array}$ & $\begin{array}{c}\text { F2 } \\
\text { (Advanced services category) }\end{array}$ & $\begin{array}{c}\text { F3 } \\
\text { (protection factor-economy) }\end{array}$ & $\begin{array}{c}\mathrm{F} 4 \\
\text { (protection factor-resources) }\end{array}$ \\
\hline General public services & Teach educate & Social security and employment & $\begin{array}{l}\text { Weather and other matters of } \\
\text { land and resources }\end{array}$ \\
\hline Country anti & Science and technology & Housing security spending & Grain and oil stockpiles affairs \\
\hline Public safety & $\begin{array}{l}\text { Urban and rural community } \\
\text { affairs }\end{array}$ & Debt servicing expenses & \\
\hline Culture, sport and media & $\begin{array}{l}\text { Business services and other } \\
\text { matters }\end{array}$ & $\begin{array}{l}\text { Financial regulatory affairs } \\
\text { expenses }\end{array}$ & \\
\hline \multicolumn{4}{|l|}{ Health } \\
\hline \multicolumn{4}{|l|}{ Energy saving } \\
\hline \multicolumn{4}{|l|}{$\begin{array}{l}\text { Agriculture, forestry and } \\
\text { water affairs }\end{array}$} \\
\hline \multicolumn{4}{|l|}{ Transportation } \\
\hline $\begin{array}{l}\text { Resource exploration power } \\
\text { information and other matters }\end{array}$ & & & \\
\hline
\end{tabular}


service class. And education, science and technology, urban and rural community affairs, business services and other services for the most part in order to improve the standard of living, so that scientific and technological innovation and development expenditure, classified as high-level service class, and social security and employment, housing security spending, national debt also The interest expenses, financial regulation and other matters belong to the social security expenditure category, but tend to be more security spending in the economic field, and therefore classified as economic factors in child protection factor. Expenditure land resources and meteorological affairs, grain stockpiles affairs in these two areas are resource protection areas to protect the class, so it is classified as resource protection factor of sub-factors.

Basic service class, senior class service, guarantee factor (economy), protection factor (resources) of the four main components constitute the basic pattern of expenditure structure of local government finances, the research on the relationship between the structure of fiscal expenditure and economic growth in the subsequent offer foundation.

\section{Cluster Analysis}

Determined by factor analysis Chinese local government financial expenditure structure, and as explanatory variables and economic growth variables correlation analysis and regression analysis, high-level service class factor stimulating effect on economic growth, fiscal spending should increase high-level service class factor you can promote economic growth. Learn Chinese local government's fiscal expenditure structure and regional distribution differences contribute to propose appropriate policy recommendations targeted.

This part of the systematic approach of clustering structure of local government finance expenditure categories, tendentious analysis of various types of expenditure in the provincial government and to local government expenditure structural differences cause analysis, to improve the structure of fiscal expenditure provided recommendations. Cluster analysis mainly factor analysis of provincial government spending to get a score of basic data, using software SPSS18.0 clustering results obtained, as shown in Table 5.

Table 5 shows that the provinces are divided into five categories, which are divided into three categories of the second category. According to the provincial government further factor scores calculated the scores of various types of expenditure areas, as shown in Table 6.

Table 6 shows that: Integrated financial expenditure structure of local government in the country is more balanced. Where basic services category, advanced services category, protection factor-the economy, the protection factor-resources that expenditure score four little difference, respectively, of $0.724,0.256,0.202,0.654$ points, which may be the central government transfer payments narrowed each regional differences in the structure of fiscal expenditure; the presence of local government fiscal expenditure structure significant regional differences, Class I Beijing, Tianjin, Shanghai, the main factor tends to advanced services spending, expenditure in this area amounted to 2.822 score the most, has an important relationship with the level of development in these areas.

Fiscal expenditure structure type II region overall score is generally not high, but more balanced structure of financial expenditure score convergence, are concentrated around zero, the kind of area that contains 24 provinces, accounting for 77.42 percent of the total provincial, and local governments features similar overall expenditure.

Table 5. Local government expenditure clustering results.

\begin{tabular}{lll}
\hline Category & Province \\
\hline Class I & Beijing, Tianjin, Shanghai \\
& 1st subcategories & $\begin{array}{l}\text { Hebei, Liaoning, Jiangsu, Zhejiang, Anhui, Fujian, Jiangxi, Shandong, Henan, Hubei, } \\
\text { Hunan, Guangdong, Guangxi, Chongqing, Sichuan, Guizhou, Yunnan, Shaanxi, Gansu }\end{array}$ \\
Class II & 2nd subcategories & Shanxi, Jilin, Heilongjiang \\
& 3rd subcategories & Hainan, Xinjiang \\
Class III & & Inner Mongolia \\
Class IV & Tibet \\
Class V & Qinghai, Ningxia \\
\hline
\end{tabular}


Table 6. Expenditure regional scores.

\begin{tabular}{llcccc}
\hline & Category & $\begin{array}{c}\text { Basic service } \\
\text { class }\end{array}$ & $\begin{array}{c}\text { Advanced services } \\
\text { category }\end{array}$ & $\begin{array}{c}\text { Protection factor } \\
\text { - economy }\end{array}$ & $\begin{array}{c}\text { Protection factor } \\
\text {-resources }\end{array}$ \\
\hline Class I & & -0.026 & 2.822 & -0.314 & -0.286 \\
& 1st subcategories & -0.270 & -0.359 & -0.216 & -0.390 \\
& 2nd subcategories & -0.421 & -0.396 & -0.337 & 1.503 \\
Class II & 3rd subcategories & 0.453 & -0.307 & 0.332 & -0.244 \\
& Synthesize & -0.079 & -0.354 & -0.074 & 0.290 \\
Class III & & 0.022 & 0.298 & -0.772 & 3.856 \\
Class IV & & 5.077 & -0.397 & -0.724 & -0.114 \\
Class V & & 0.232 & 0.130 & 3.442 & 0.252 \\
Synthesize & 0.724 & 0.256 & 0.202 & .654 \\
\hline
\end{tabular}

From this category is subdivided into three categories, subcategories provinces observe three characteristics of financial expenditure, Shanxi, Jilin, Heilongjiang fiscal spending in the protection factor-the higher expenditure of resources, and the protection factor-primarily land and resource expenditures Resources meteorological affairs, grain stockpiles affairs, which is rich in resources in Shanxi coal mine, Jilin and Heilongjiang rich aquatic resources led to increased expenses related to the grain reserve. Hainan, Xinjiang major classes tend to basic services and security factors-economic class, may be related to the remote terrain, the demand for basic services is the main reason for the high. The second category are classified as a subset of the other provinces, the categories including Hebei, Liaoning, Jiangsu, Zhejiang, Anhui, Fujian, Jiangxi, Shandong, Henan, Hubei, Hunan, Guangdong, Guangxi, Chongqing, Sichuan, Guizhou, Yunnan, Shaanxi, Gansu, in the structure of fiscal expenditure showed no significant differences, while a more balanced spending shortfalls.

Class III Inner Mongolia in the structure of fiscal expenditure tend to protect the main factor (resource), scoring 3.856, which may be due mainly to the grasslands of Inner Mongolia and other resource supply as the main feature, the maintenance of a large number of financial expenditure in grain and oil reserves, while Inner Mongolia's unique geographical location also makes it to increase spending in meteorology land resources.

Type IV for Tibet, Tibet on the main structure of fiscal expenditure category tend to basic services, and the differences in the financial structure of spending large class score 5.077 to basic services, and advanced services, protection factor - the economy, the protection factor-resource scores were is $-0.397,-0.724,-0.114$, indicating that the local government in Tibet and people are more inclined to demand basic services, this area is more than 90 percent of Tibet expenditure from the central transfer payments, and transfers the main The formation of a special fiscal expenditure structure [15] for basic services. On the other hand may be more related to national identity in Tibetan areas, ethnic composition and other factors lead to differences in demand for public services to bring the cost of public service delivery and economic and social development [16], while the other three should be noted expenditure is very weak, inadequate spending.

The first class V Qinghai and Ningxia, speaking generally higher from the fiscal expenditure structure, which safeguards factors-economic class spending the highest score of 3.442, while the protection factor-economics major expenditure including social security and employment, housing security spending, debt service expenditures, financial regulatory affairs spending, indicating Qinghai, Ningxia region at affordable expenses higher expenditure for the livelihood of the majority.

\section{Conclusions}

Principal component expenditure is as a variable system clustering; the financial structure of local government spending in the country is divided into five categories; the distribution of the difference is obvious. It should be mentioned as the economic development agenda on fiscal restructuring expenses, and in particular with the standard financial transfer payment to drive balanced developments among different regions.

From the scores of senior regional service expenditure structure factors, we can see that Class I of Beijing, 
Tianjin, Shanghai maintains the highest degree; Class III and V are Inner Mongolia, Qinghai, Ningxia followed by the first class; Class II and IV of the total 25 regions' advanced services factor have the lowest level, suggesting that we should focus on improving the quantity and quality of expenditure of Shanxi, Hebei, Liaoning, Tibet and others to promote economic growth more effectively.

\section{References}

[1] Solow, R.M. (1956) A Contribution to the Theory of Economic Growth. The Quarterly Journal of Economics, 70, 6594. http://dx.doi.org/10.2307/1884513

[2] Swan, T.W. (1956) Economic Growth and Capital Accumulation. Economic Record, 32, 334-361. http://dx.doi.org/10.1111/j.1475-4932.1956.tb00434.x

[3] Barro, R.J. (1991) Government Spending in a Simple Model of Endogenous Growth. Journal of Political Economy, 98, S103-S125. http://dx.doi.org/10.1086/261726

[4] Lucas, R.E. (1990) Supply-Side Economics: An Analytical Review. Oxford Economic Papers, New Series, 42, 293316.

[5] Grier, K.B. and Tullock, G. (1989) An Empirical Analysis of Cross-National Economic Growth, 1951-1980. Journal of Monetary Economics, 24, 259-276. http://dx.doi.org/10.1016/0304-3932(89)90006-8

[6] Aschauer, D. (1989) Is Government Spending Productive? Journal of Monetary Economics, 23, 177-200. http://dx.doi.org/10.1016/0304-3932(89)90047-0

[7] Easterly, W. and Rebelo, S. (1993) Fiscal Policy and Economic Growth: An Empirical Investigation. Journal of Monetary Economics, 32, 417-458. http://dx.doi.org/10.1016/0304-3932(93)90025-B

[8] Afonso, A. and Furceri, D. (2010) Government Size, Composition, Volatility and Economic Growth. European Journal of Political Economy, 26, 517-532. http://dx.doi.org/10.1016/j.ejpoleco.2010.02.002

[9] Gong, L.T. and Zou, H.F. (2001) Affect Growth and Volatility of Public Expenditure on Economic Growth. Dynamic Economics, 9, 58-63.

[10] Gupta, S., Clements, B., Baldacci, E., et al. (2005) Fiscal Policy, Expenditure Composition, and Growth in Low-Income Countries. Journal of International Money and Finance, 24, 441-463.

[11] Guo, Q.W., Lv, B.Y. and Zhang, D.Y. (2003) Fiscal Expenditure Structure and Economic Growth. Economic Theory and Business Management, 11, 5-12.

[12] Ramey, V.A. (2011) Can Government Purchases Stimulate the Economy? Journal of Economic Literature, 49, 673685. http://dx.doi.org/10.1257/jel.49.3.673

[13] Colombier, C. (2011) Does the Composition of Public Expenditure Affect Economic Growth? Evidence from the Swiss Case. Applied Economics Letters, 18, 1583-1589. http://dx.doi.org/10.1080/13504851.2011.554361

[14] Zhang, G. and Duan, C. (2006) Empirical Study of Local Fiscal Expenditure Structure of Our Country and Economic Growth in the Region. Journal of Zhejiang University (Social Science Edition), 2, 88-94.

[15] Kuang, X.P. and Yang, D.Q. (2013) Empirical Study of Chinese Local Fiscal Expenditure Structure Based on Factor Analysis and Cluster Analysis. Chinese Administration, 1, 105-110.

[16] Heshmati, A. (2001) On the Causality between GDP and Health Care Expenditure in Augmented Solow Growth Model. SSE/EFI Working Paper Series in Economics and Finance. 